\title{
Relationship between time elapsed since completion of radiotherapy and quality of life of patients with breast cancer
}

\author{
Jing-Jie Zhang ${ }^{1 \dagger}$, Hang Shu ${ }^{2 \dagger}$, Shuai-Shuai Hư ${ }^{2}$, Yang Yu ${ }^{2}$, Yi Sun ${ }^{2}$ and Yin $\mathrm{Lv}^{3^{*}}$
}

\begin{abstract}
Background: To investigate the relationship between time elapsed since completion of radiotherapy (RT) and quality of life (QOL) of patients with breast cancer.

Methods: A total of 300 patients with breast cancer were treated at the First Affiliated Hospital of Anhui Medical University between January 2013 and April 2016. Of these, 212 patients were included in the study. Patients were divided into 4 groups based on the time elapsed since completion of RT. The generic cancer questionnaire, EORTC QLQ30, and the breast cancer-specific questionnaire, QLQ-BR23, were used to assess the QOL.

Results: Analysis of time elapsed since completion of RT and QOL revealed changes in the scores for role function with passage of time; the third year's scores were the highest. Pain symptoms during the 3rd and 4th years after RT were lower than those during the 1st and 2nd years after RT; scores for financial difficulties fluctuated with passage of time; perception of own body scores improved within first 3 years; sexual activity and enjoyment of sexual activity showed a significant decrease during the 2 nd to 4 th year post RT. Scores pertaining to concerns about future state of health showed a significant increase during the 2nd to 4th year after RT, while breast symptoms score showed fluctuations with passage of time.
\end{abstract}

Conclusions: Social function, pain symptoms, and concerns about future state of health tended to improve with passage of time after RT. Other scales showed no correlation with time elapsed since completion of RT.

Keywords: Quality of life, Breast cancer, Time after Radiotherapy, EORTC

\section{Background}

Globally, breast cancer is the most common malignancy and the leading cause of cancer-related deaths among women $[1,2]$. In the United States, one in eight women will develop breast cancer during their lifetime [3]. Management of breast cancer includes surgery followed by radiotherapy (RT). Other treatment approaches include chemotherapy, endocrine therapy, and molecular targeted therapy [4]. Breast cancer remission in most cases is accompanied by concomitant short and/or long term damage to the physiological structure and function [510]. This could ultimately limit the patients' activities of

\footnotetext{
* Correspondence: Lvyin406@163.com

${ }^{\dagger}$ Equal contributors

${ }^{3}$ Department of Radiotherapy, The First Affiliated Hospital of Anhui Medical

University, No. 281 Jixi Road, Hefei, Anhui 230022, China

Full list of author information is available at the end of the article
}

daily living and represent a source of long term impairment [8-14].

Advances in early diagnosis and treatment of breast cancer have helped improve patient survival. Consequently, the number of people living with disease sequelae is projected to increase over time. Providing long-term health care to these patients and measuring the impact of these services are pragmatic approaches. Assessment of cancer-specific quality of life (QOL) is an ideal approach towards this end. The European Organization Research and Treatment of Cancer (EORTC) QLQ-C30 questionnaire is a widely used instrument to assess the QOL of cancer patients [15]. Its specific module on breast cancer is the EORTC QLQBR23 [16]. Several studies have focused on the association between various treatment modalities (such as, surgical approach, radiation and chemotherapy regime 
or endocrine therapy) and QOL of patients with breast cancer [17]. However, few studies have investigated the temporal changes in QOL of these patients after completion of radiotherapy.

In the present study, we assessed the QOL of breast cancer patients at different time intervals after completion of RT using EORTC QLQ-C30 and EORTC QLQBR23 questionnaires. The objective was to assess whether time elapsed since completion of RT has a bearing on the QOL of these patients.

\section{Methods}

\section{Study design}

Patients with breast cancer were recruited at the Department of Radiation Oncology at the First Affiliated Hospital of Anhui Medical University, from January 2013 to April 2016. Breast cancer patients who received RT post surgery were enrolled in the study. Written informed consent was obtained from all patients prior to their enrolment. The study was approved by the ethics committee of The First Affiliated Hospital of Anhui Medical University.

\section{Implementation of questionnaire survey}

Patients were divided into four groups based on time elapsed since completion of radiotherapy (0-1.5 years; $1.5-2.5$ years; $2.5-3.5$ years; and $3.5-4.5$ years). Patients were administered both EORTC QLQ-C30 and QLQBR23 questionnaires. QLQ-C30 is a generic questionnaire used to assess patients with various tumors, while QLQ-BR23 is a breast cancer-specific questionnaire.

\section{Statistical analysis}

Epidata 3.0 was used for data entry. Data are presented as mean \pm standard deviation (SD) or as frequencies (percentages). ANOVA test was used to compare the QOL at different time intervals post RT. Multiple regression model was used to conduct multivariate analysis. Variables included in the model were age, educational level, surgical technique, surgical staging, number of chemotherapy cycles, and time elapsed since completion of RT. All statistical analyses were performed using SSPS 13.0 (SAS Institute, Inc., Cary, North Carolina); $p$ values $<0.05$ were considered statistically significant.

\section{Results}

\section{Patient characteristics}

A total of 300 patients who had undergone surgery for breast cancer were enrolled in the study; Patients were followed up in March 2017. The valid number of patients is 212 (80 patients were lost to follow-up and eight patients died). The median follow-up time was 27.2 months. The number of patients followed up for 0 to 1.5 years, 1.5 to 2.5 years, 2.5 to 3.5 years and 3.5 to 4.5 years were 64 , 61, 66 and 21, respectively. Patient characteristics are listed in Table 1 . The mean $( \pm \mathrm{SD})$ age of patients was $48.36 \pm 8.95$ years. About $11.3 \%$ of patients were illiterate; $28.8 \%$ were educated up to primary school level, $43.9 \%$ were educated up to middle school and $16.0 \%$ of patients were educated up to college level or above. More than 95.3\% of patients were married. Most patients had stage II (53.3\%) or III (37.3\%) disease. Percentages of patients who had received breast-conserving surgery, breast reconstruction surgery and modified radical mastectomy were $22.2 \%$, $5.2 \%$ and $72.6 \%$, respectively (Table 1 ).

\section{Univariate analysis of EORTC QLQ-C30 data}

Of the 15 subscales, only the role function, social function, pain and financial impact of disease scores exhibited significant changes over time after radiotherapy $(p<$ 0.002). Of these, the role function score showed the highest level in the 2.5 to 3.5 years time window postradiotherapy. Pain scores in the 2.5 to 4.5 years time window post- radiotherapy were significantly lower than those in the 0 to 2.5 years time window, which indicates subsidence of pain over time. The scores for financial impact of disease showed fluctuations over time $(45.83 \pm 33.60$, $42.86 \pm 36.67,18.10 \pm 29.53$ and $53.33 \pm 50.18$ in the 0 1.5 ; $1.5-2.5 ; 2.5-3.5$; and $3.5-4.5$ years groups, respectively). The economic impact was found to be lower during the time window of 2.5 to 3.5 years since completion of RT. The total QOL score did not change significantly in different time intervals post RT with respect to the other subscales of function and clinical symptoms (Table 2).

\section{Univariate analysis of EORTC QLQ-BR23 data}

Statistically significant between-group differences were observed with respect to scores for perception of own

Table 1 Patients' characteristics

\begin{tabular}{lll}
\hline Variables & & Mean \pm SD or n (\%) \\
\hline Age (years) & & $48.36 \pm 8.95$ \\
Level of education & Illiterate & $24(11.3)$ \\
& Primary School & $61(28.8)$ \\
& Middle School & $93(43.9)$ \\
& College or above & $34(16.0)$ \\
Marital status & Unmarried & $10(4.7)$ \\
& Married & $202(95.3)$ \\
Clinical stage & 0 & $2(0.9)$ \\
& I & $11(5.2)$ \\
& II & $113(53.3)$ \\
Surgical technique & Breast-conserving surgery & $47(22.2)$ \\
& Breast reconstruction surgery & $11(5.2)$ \\
& Modified radical mastectomy & $154(72.6)$ \\
\hline
\end{tabular}


Table 2 Results of univariate analysis of EORTC QLQ-C30 questionnaire data

\begin{tabular}{|c|c|c|c|c|c|c|}
\hline \multirow{2}{*}{$\frac{\text { Scale }}{\text { Functional scales }}$} & \multicolumn{4}{|c|}{ Time elapsed since completion of radiotherapy } & \multirow[t]{2}{*}{ F-value } & \multirow[t]{2}{*}{$p$-value } \\
\hline & $0-1.5$ years & $1.5-2.5$ years & $2.5-3.5$ years & $3.5-4.5$ years & & \\
\hline Physical function & $72.50 \pm 28.17$ & $71.43 \pm 22.27$ & $81.71 \pm 24.91$ & $90.00 \pm 25.38$ & 1.643 & 0.184 \\
\hline Role function & $88.28 \pm 17.94$ & $82.86 \pm 25.56$ & $95.71 \pm 9.56$ & $85.00 \pm 24.15$ & 2.715 & 0.048 \\
\hline Emotional function & $89.38 \pm 21.54$ & $90.00 \pm 13.93$ & $84.00 \pm 20.75$ & $81.00 \pm 21.83$ & 1.054 & 0.372 \\
\hline Cognitive function & $76.56 \pm 22.84$ & $80.00 \pm 17.99$ & $71.43 \pm 30.40$ & $77.50 \pm 14.19$ & 0.788 & 0.503 \\
\hline Social function & $80.73 \pm 25.79$ & $79.52 \pm 16.71$ & $93.33 \pm 16.27$ & $91.67 \pm 11.79$ & 4.014 & 0.009 \\
\hline \multicolumn{7}{|l|}{ Symptom scales } \\
\hline Tiredness & $26.82 \pm 29.83$ & $23.38 \pm 28.43$ & $20.53 \pm 27.59$ & $3.99 \pm 12.62$ & 1.801 & 0.151 \\
\hline Nausea/vomiting & $2.08 \pm 7.02$ & $3.81 \pm 17.66$ & $3.33 \pm 9.74$ & $0.00 \pm 0.00$ & 0.329 & 0.804 \\
\hline Pain & $35.42 \pm 31.61$ & $37.14 \pm 33.11$ & $18.10 \pm 29.53$ & $16.67 \pm 23.57$ & 3.261 & 0.024 \\
\hline Shortness of breath & $9.38 \pm 29.61$ & $5.71 \pm 23.55$ & $11.43 \pm 32.28$ & $10.00 \pm 31.62$ & 0.238 & 0.870 \\
\hline Sleep disturbance & $9.38 \pm 17.42$ & $6.67 \pm 17.71$ & $14.29 \pm 23.27$ & $10.00 \pm 31.62$ & 0.790 & 0.502 \\
\hline Lack of appetite & $9.38 \pm 29.61$ & $8.57 \pm 28.40$ & $8.57 \pm 28.40$ & $10.00 \pm 31.62$ & 0.011 & 0.998 \\
\hline Constipation & $7.29 \pm 18.42$ & $3.81 \pm 10.76$ & $6.67 \pm 13.53$ & $20.00 \pm 42.16$ & 2.013 & 0.116 \\
\hline Diarrhea & $3.13 \pm 17.68$ & $1.43 \pm 8.45$ & $1.43 \pm 8.45$ & $0.00 \pm 0.00$ & 0.243 & 0.866 \\
\hline Financial impact of disease & $45.83 \pm 33.60$ & $42.86 \pm 36.67$ & $18.10 \pm 29.53$ & $53.33 \pm 50.18$ & 5.107 & 0.002 \\
\hline Overall state of health & $76.82 \pm 14.16$ & $76.67 \pm 14.12$ & $68.10 \pm 24.63$ & $76.67 \pm 10.10$ & 1.863 & 0.140 \\
\hline
\end{tabular}

body, sexual activity, enjoyment of sexual activity, concerns about future state of health and symptoms in the breast $(P<0.05)$. The scores for perception of own body increased during the 0 to 3.5 years time window after $\mathrm{RT}$, and then decreased during the 3.5 to 4.5 years time window. Similar trend was observed with respect to the subscales of sexual activity and enjoyment of sexual activity in that the scores dropped significantly during the 2.5 to 4.5 year time window as compared to those during the 0 to 2.5 year time window after completion of RT. On the contrary, the scores for concerns about future state of health rose significantly during the 2.5 to 4.5 year time window as compared with that during the 0 to 2.5 year time window after completion of RT. The scores for subscale of symptoms in the breast fluctuated; the highest scores pertained to the 0 to 1.5 year time window after completion of RT (Table 3).

\section{Results of multivariate linear regression analysis}

On multivariate analysis, time elapsed since completion of RT was an independent predictor of social function, pain, and concerns about future state of health $(p=$ $0.003, p=0.011$, and $p=0.013$, respectively) (Tables 4 and 5).

\section{Discussion}

The present study is among the few studies which have evaluated the effect of time elapsed since completion of radiotherapy on the QOL of breast cancer patients following breast surgery using the EORTC QLQ-C30

Table 3 Results of univariate analysis of EORTC QLQ-BR23 questionnaire data

\begin{tabular}{|c|c|c|c|c|c|c|}
\hline \multirow{2}{*}{$\frac{\text { Scale }}{\text { Functional scales }}$} & \multicolumn{4}{|c|}{ Time elapsed since completion of radiotherapy } & \multirow[t]{2}{*}{ F-value } & \multirow[t]{2}{*}{$p$-value } \\
\hline & $0-1.5$ years & $1.5-2.5$ years & $2.5-3.5$ years & $3.5-4.5$ years & & \\
\hline Perception of own body & $82.29 \pm 25.02$ & $90.24 \pm 14.50$ & $94.52 \pm 11.06$ & $88.33 \pm 15.81$ & 2.800 & 0.043 \\
\hline Sexual activity & $81.77 \pm 26.22$ & $89.52 \pm 22.17$ & $71.90 \pm 27.05$ & $76.67 \pm 35.31$ & 2.735 & 0.047 \\
\hline Enjoyment of sexual activity & $83.33 \pm 26.76$ & $91.43 \pm 20.36$ & $71.43 \pm 28.17$ & $76.67 \pm 35.31$ & 3.546 & 0.017 \\
\hline Concerns about future state of health & $71.88 \pm 33.45$ & $74.29 \pm 30.61$ & $92.86 \pm 17.75$ & $85.00 \pm 24.15$ & 4.048 & 0.009 \\
\hline \multicolumn{7}{|l|}{ Symptom scales } \\
\hline Side-effects of therapy & $23.44 \pm 23.52$ & $30.00 \pm 28.81$ & $21.42 \pm 24.11$ & $38.33 \pm 23.64$ & 1.549 & 0.206 \\
\hline Symptoms in the breast & $32.81 \pm 32.03$ & $17.86 \pm 20.63$ & $17.14 \pm 22.50$ & $25.00 \pm 16.67$ & 2.851 & 0.041 \\
\hline Symptoms in arm/shoulder & $15.66 \pm 20.44$ & $13.84 \pm 18.00$ & $9.31 \pm 9.88$ & $20.05 \pm 14.31$ & 1.480 & 0.224 \\
\hline Low mood because of hair loss & $1.56 \pm 8.84$ & $4.29 \pm 18.67$ & $4.29 \pm 14.20$ & $10.00 \pm 21.08$ & 0.796 & 0.499 \\
\hline
\end{tabular}


Table 4 Variables showing no significant association with time elapsed since radiotherapy on multivariate analyses

\begin{tabular}{|c|c|c|c|c|c|}
\hline Variables & Regression coefficients & Standard error & Standard regression coefficient & $t$ & $p$-value \\
\hline \multicolumn{6}{|l|}{ Role function } \\
\hline Constant term & 75.366 & 18.565 & & & \\
\hline Age & 0.473 & 0.215 & 0.214 & 2.200 & 0.030 \\
\hline Level of education & 2.609 & 2.232 & 0.121 & 1.169 & 0.245 \\
\hline Surgical technique & -0.220 & 2.450 & -0.009 & -0.090 & 0.929 \\
\hline Surgical staging & -5.807 & 3.145 & -0.189 & -1.846 & 0.068 \\
\hline Number of chemotherapy cycles & -0.137 & 0.976 & -0.014 & -0.141 & 0.888 \\
\hline Time elapsed since completion of RT & 2.231 & 1.977 & 0.108 & 1.129 & 0.262 \\
\hline \multicolumn{6}{|l|}{ Financial impact of disease } \\
\hline Constant term & 76.843 & 31.830 & & & \\
\hline Age & 0.392 & 0.369 & 0.095 & 1.062 & 0.291 \\
\hline Degree of education & -14.859 & 3.827 & -0.370 & -3.883 & 0.000 \\
\hline Surgical technique & 7.793 & 4.201 & 0.174 & 1.855 & 0.066 \\
\hline Surgical staging & -13.631 & 5.393 & -0.237 & -2.528 & 0.013 \\
\hline Number of chemotherapy cycles & 2.638 & 1.673 & 0.139 & 1.576 & 0.118 \\
\hline Time elapsed since completion of RT & -3.202 & 3.390 & -0.083 & -0.944 & 0.347 \\
\hline \multicolumn{6}{|l|}{ Perception of own body } \\
\hline Constant term & 32.595 & 16.150 & & & \\
\hline Age & 0.429 & 0.187 & 0.215 & 2.292 & 0.024 \\
\hline Level of education & 6.407 & 1.942 & 0.329 & 3.300 & 0.001 \\
\hline Surgical technique & -0.084 & 2.131 & -0.004 & -0.039 & 0.969 \\
\hline Surgical staging & 4.279 & 2.736 & 0.154 & 1.564 & 0.121 \\
\hline Number of chemotherapy cycles & -0.563 & 0.849 & -0.061 & -0.663 & 0.508 \\
\hline Time elapsed since 'completion of RT & 3.219 & 1.720 & 0.173 & 1.871 & 0.064 \\
\hline \multicolumn{6}{|l|}{ Sexual activity } \\
\hline Constant term & 60.288 & 23.972 & & & \\
\hline Age & 0.810 & 0.278 & 0.270 & 2.916 & 0.004 \\
\hline Level of education & -4.535 & 2.882 & -0.156 & -1.574 & 0.119 \\
\hline Surgical technique & -0.926 & 3.164 & -0.029 & -0.293 & 0.770 \\
\hline Surgical staging & 3.943 & 4.061 & 0.095 & 0.971 & 0.334 \\
\hline Number of chemotherapy cycles & -1.596 & 1.260 & -0.116 & -1.267 & 0.208 \\
\hline Time elapsed since completion of RT & -3.547 & 2.553 & -0.127 & -1.389 & 0.168 \\
\hline \multicolumn{6}{|l|}{ Enjoyment of sexual activity } \\
\hline Constant term & 55.928 & 23.971 & & & \\
\hline Age & 0.830 & 0.278 & 0.274 & 2.989 & 0.003 \\
\hline Level of education & -4.352 & 2.882 & -0.147 & -1.510 & 0.134 \\
\hline Surgical technique & -0.105 & 3.164 & -0.003 & -0.033 & 0.974 \\
\hline Surgical staging & 5.184 & 4.061 & 0.123 & 1.277 & 0.205 \\
\hline Number of chemotherapy cycles & -1.677 & 1.260 & -0.120 & -1.330 & 0.186 \\
\hline Time elapsed since completion of RT & -4.524 & 2.553 & -0.160 & -1.772 & 0.079 \\
\hline \multicolumn{6}{|l|}{ Symptoms in the breast } \\
\hline Constant term & 42.090 & 24.453 & & & \\
\hline Age & -0.080 & 0.283 & -0.028 & -0.282 & 0.778 \\
\hline Level of education & -1.213 & 2.940 & -0.044 & -0.413 & 0.681 \\
\hline
\end{tabular}


Table 4 Variables showing no significant association with time elapsed since radiotherapy on multivariate analyses (Continued)

\begin{tabular}{|c|c|c|c|c|c|}
\hline Variables & Regression coefficients & Standard error & Standard regression coefficient & $t$ & $p$-value \\
\hline Surgical technique & -2.557 & 3.227 & -0.083 & -0.792 & 0.430 \\
\hline Surgical staging & 0.934 & 4.143 & 0.024 & 0.225 & 0.822 \\
\hline Number of chemotherapy cycles & 0.097 & 1.285 & 0.007 & 0.076 & 0.940 \\
\hline Time elapsed since completion of RT & -4.410 & 2.604 & -0.167 & -1.693 & 0.093 \\
\hline
\end{tabular}

and EORTC QLQ-BR23 instruments. We found that the patients' social function, as measured with the EORTC QLQ-C30, improved significantly with passage of time during the 2.5 to 4.5 year time window after completion of RT. Social function refers to the patient's selfawareness about his/her own health status and the impact on family's daily life and social activities. A previous study revealed poor QOL of family caregivers of patients with cancers [18]. Strain imposed by cancer associated pain and discomfort, impaired capacity for work, and the dependence on drugs and adjuvant therapy can affect the physical condition of family caregivers, and render them vulnerable to cognitive dysfunction and sleep disorders. The major causes that impair posttreatment social life of patients with breast cancer include physical changes (such as removal of mammary gland), pain, and psychological factors such as depression, irritability and anxiety [19-21]. With passage of time after completion of radiotherapy, patients tend to gradually accept the reality, which helps improve their social adaptability [22-24].

Breast, arm, and shoulder pain are commonly experienced by breast cancer patients after treatment [25, 26]; these were shown to significantly impair the long-term QoL of these patients [27]. These symptoms may be attributable to tumor metastasis, anti-cancer therapy or to social-psychological factors. Previous studies have identified age, axillary lymph node dissection, and postoperative RT as significant risk factors $[25,28]$. In the present study, only time elapsed since completion of RT was

Table 5 Variables showing a significant association with time elapsed since radiotherapy on multivariate analyses

\begin{tabular}{|c|c|c|c|c|c|}
\hline Variables & Regression coefficients & Standard error & Standard regression coefficient & t-value & $p$-value \\
\hline \multicolumn{6}{|l|}{ Social function } \\
\hline Constant term & 70.104 & 17.984 & & & \\
\hline Age & -0.161 & 0.208 & -0.071 & -0.770 & 0.443 \\
\hline Level of education & 2.500 & 2.162 & 0.114 & 1.156 & 0.250 \\
\hline Surgical technique & -5.585 & 2.373 & -0.230 & -2.353 & 0.020 \\
\hline Surgical staging & 1.787 & 3.047 & 0.057 & 0.586 & 0.559 \\
\hline Number of chemotherapy cycles & 1.804 & 0.945 & 0.175 & 1.908 & 0.059 \\
\hline Time elapsed since completion of RT & 5.787 & 1.915 & 0.276 & 3.022 & 0.003 \\
\hline \multicolumn{6}{|l|}{ Pain } \\
\hline Constant term & -0.578 & 29.509 & & & \\
\hline Age & 0.664 & 0.342 & 0.187 & 1.941 & 0.055 \\
\hline Level of education & 6.030 & 3.548 & 0.175 & 1.700 & 0.092 \\
\hline Surgical technique & -1.481 & 3.894 & -0.038 & -0.380 & 0.704 \\
\hline Surgical staging & 0.919 & 5.000 & 0.019 & 0.184 & 0.854 \\
\hline Number of chemotherapy cycles & -0.106 & 1.551 & -0.006 & -0.068 & 0.946 \\
\hline Time elapsed since completion of RT & -8.118 & 3.143 & -0.245 & -2.583 & 0.011 \\
\hline \multicolumn{6}{|l|}{ Concerns about future state of health } \\
\hline Constant term & -0.280 & 25.906 & & & \\
\hline Age & 0.237 & 0.300 & 0.074 & 0.788 & 0.432 \\
\hline Level of education & 6.092 & 3.115 & 0.195 & 1.956 & 0.053 \\
\hline Surgical technique & -3.303 & 3.419 & -0.095 & -0.966 & 0.336 \\
\hline Surgical staging & 13.289 & 4.389 & 0.297 & 3.028 & 0.003 \\
\hline Number of chemotherapy cycles & -0.131 & 1.362 & -0.009 & -0.096 & 0.923 \\
\hline Time elapsed since completion of RT & 6.974 & 2.759 & 0.233 & 2.528 & 0.013 \\
\hline
\end{tabular}


found to be associated with reduction in pain, after adjusting for age, educational level of patients, operation method, surgical staging and number of chemotherapy cycles; pain relief was especially noticeable after 2.5 to 4.5 years post-radiotherapy.

Scores pertaining to concerns about future state of health showed improvement from 2.5 to 3.5 years postradiotherapy and a slight decline was also observed during the 3.5 to 4.5 year time window post-radiotherapy. The diagnosis and cure of breast cancer are both typically life-changing events which affect the patient's psychological health [29]. At initial diagnosis, the patient typically experiences the psychological phenomenon of denial, anger, acceptance, depression, fear and survival, short-term lack of confidence and even fear for future health. Although the negative effects of disease on the patient exist, the positive effects of post-traumatic growth, however, helps augment patient's confidence and reduces their worries about future [30]. More importantly, the confidence of patients is reinforced by the negative results of the annual cancer re-examination. Additionally, the recovery of functions in various aspects promotes the normal activities of daily living, which enable the patients to look forward to the future [24].

The cross-sectional study design is the main limitation of this study. The design does not allow for causal inferences, but only describes the factors associated with selfreported QoL outcomes.

\section{Conclusions}

In this study cohort, time elapsed since completion of RT had significant impact on social function, pain symptoms, and concerns about future state of health of patients with breast cancer. These scales improved with passage of time after RT. Our results have profound guiding significance for QOL of patients with breast cancer after RT. Of note, breast cancer is a heterogeneous disease and these results are limited to the crosssectional study. Further studies are needed to elucidate the possible impact of time elapsed since completion of RT on breast cancer patients.

\section{Abbreviations}

EORTC: European Organization Research and Treatment of Cancer; QOL: Quality of life; RT: Radiotherapy; SD: Standard deviation

\section{Acknowledgements}

Not applicable.

\section{Funding}

This work was supported by Major projects of Natural Science Foundation of universities in Anhui Province (KJ2016SD26, 2016-2018). The authors declare that they have no financial relationship with the organization that sponsored the research, and the funding body was not involved in study design, data collection, analysis and writing of the study.

\section{Availability of data and materials}

The data sets generated during and/or analysed during the current study are not publicly available due to confidentially reasons but are available from the corresponding author on reasonable request.

\section{Authors' contributions}

YL and JJZ designed the study. JJZ, HS, SSH, YY, YS, and YL collected and analyzed the data. HS and JJZ contributed samples collection and intellectual input. YL and HS drafted and wrote the manuscript. HS, SSH, YY and YS revised the manuscript critically for intellectual content. All authors gave intellectual input to the study and approved the final version of the manuscript.

\section{Ethics approval and consent to participate}

The study was approved by the ethics committee of The First Affiliated Hospital of Anhui Medical University. All procedures performed in studies involving human participants were in accordance with the ethical standards of the institutional and national research committee and with the 1964 Helsinki declaration and its later amendments or comparable ethical standards. Informed consent was obtained from all individual participants included in the study. Written informed consent was obtained from all patients prior to their enrolment.

\section{Consent for publication}

Not applicable.

\section{Competing interests}

The authors declare that they have no competing interests.

\section{Publisher's Note}

Springer Nature remains neutral with regard to jurisdictional claims in published maps and institutional affiliations.

\section{Author details}

${ }^{1}$ Department of Breast surgery, The First Affiliated Hospital of Anhui Medical University, Hefei 230022, China. ${ }^{2}$ Anhui Medical University, Hefei 230000, China. ${ }^{3}$ Department of Radiotherapy, The First Affiliated Hospital of Anhui Medical University, No. 281 Jixi Road, Hefei, Anhui 230022, China.

Received: 8 September 2017 Accepted: 9 March 2018

Published online: 20 March 2018

\section{References}

1. International Agency for Research on Cancer. GLOBOCAN2012. Estimated cancer incidence, mortality and prevalence worldwide in 2012. http:// globocan.iarc.fr/Pages/fact_sheets_cancer.aspx. [Accessed 27 Jan, 2017].

2. Torre LA, Bray F, Siegel RL, Ferlay J, Lortet-Tieulent J, Jemal A. Global cancer statistics, 2012. CA Cancer J Clin. 2015;65:87-108.

3. DeSantis C, Ma J, Bryan L, Jemal A. Breast cancer statistics, 2013. CA Cancer J Clin. 2014;64:52-62.

4. Krotneva S, Reidel K, Nassif M, Trabulsi N, Mayo N, Tamblyn R, et al. Rates and predictors of consideration for adjuvant radiotherapy among high-risk breast cancer patients: a cohort study. Breast Cancer Res Treat. 2013;140:397-405.

5. Ness KK, Wall MM, Oakes JM, Robison LL, Gurney JG. Physical performance limitations and participation restrictions among cancer survivors: a population-based study. Ann Epidemiol. 2006;16:197-205.

6. Mejdahl MK, Andersen KG, Gartner R, Kroman N, Kehlet H. Persistent pain and sensory disturbances after treatment for breast cancer: six year nationwide follow-up study. BMJ. 2013;346:f1865.

7. Cormier JN, Askew RL, Mungovan KS, Xing Y, Ross Ml, Armer JM. Lymphedema beyond breast cancer: a systematic review and meta-analysis of cancer-related secondary lymphedema. Cancer. 2010;116:5138-49.

8. Levangie PK, Drouin J. Magnitude of late effects of breast cancer treatments on shoulder function: a systematic review. Breast Cancer Res Treat. 2009;116:1-15.

9. Canadian Cancer Society, Statistics Canada, Public Health Agency of Canada Provincial/territorial Cancer registries: Canadian Cancer statistics special topic: liver cancer; 2013. http://www.cancer.ca/en/about-us/for-media/ media-releases/national/2013/liver-cancer-on-the-rise-cancer-statistics/ ?region=on.

10. Dawes DJ, Meterissian S, Goldberg M, Mayo NE. Impact of lymphoedema on arm function and health-related quality of life in women following breast cancer surgery. J Rehabil Med. 2008;40:651-8. 
11. Brach M, et al. ICF Core Sets for breast cancer. J Rehabil Med. 2004(44 Suppl):121-7.

12. Brockow T, et al. Identifying the concepts contained in outcome measures of clinical trials on breast cancer using the international classification of functioning, disability and health as a reference. J Rehabil Med. 2004;36:43-8.

13. Alfano CM, Smith AW, Irwin ML, Bowen DJ, Sorensen B, Reeve BB, et al. Physical activity, long-term symptoms, and physical health-related quality of life among breast cancer survivors: a prospective analysis. I Cancer Surviv. 2007;1:116-28.

14. Gilchrist LS, Galantino ML, Wampler M, Marchese VG, Morris GS, Ness KK. A framework for assessment in oncology rehabilitation. Phys Ther. 2009;89:286-306.

15. Aaronson NK, Ahmedzai S, Bergman B, Bullinger M, Cull A, Duez NJ, et al. The European Organization for Research and Treatment of Cancer QLQ-C30: a quality-of-life instrument for use in international clinical trials in oncology. J Natl Cancer Inst. 1993;85:365-76.

16. Sprangers MA, Groenvold M, Arraras JI, Franklin J, te Velde A, Muller M, et al. The European Organization for Research and Treatment of Cancer breast cancer-specific quality-of-life questionnaire module: first results from a three-country field study. J Clin Oncol. 1996;14:2756-68.

17. Montazeri A. Health-related quality of life in breast cancer patients: a bibliographic review of the literature from 1974 to 2007. J Exp Clin Cancer Res. 2008:27:32.

18. Chiou CJ, Chang HY, Chen IP, Wang HH. Social support and caregiving circumstances as predictors of caregiver burden in Taiwan. Arch Gerontol Geriatr. 2009;48:419-24.

19. Rim CH, Ahn SJ, Kim JH, Yoon WS, Chun M, Yang DS, et al. An assessment of quality of life for early phase after adjuvant radiotherapy in breast cancer survivors: a Korean multicenter survey (KROG 14-09). Health Qual Life Outcomes. 2017;15:96.

20. Sharma N, Purkayastha A. Impact of radiotherapy on psychological, financial, and sexual aspects in Postmastectomy carcinoma breast patients: a prospective study and management. Asia Pac J Oncol Nurs. 2017;4:69-76.

21. Fantoni SQ, Peugniez C, Duhamel A, Skrzypczak J, Frimat P, Leroyer A. Factors related to return to work by women with breast cancer in northern France. J Occup Rehabil. 2010;20:49-58.

22. Pehlivan S, Kuzhan A, Yildirim Y, Fadiloglu C. Comfort and quality of life in patients with breast cancer undergoing radiation therapy. J BUON. 2016;21:549-55

23. Xiao C, Miller AH, Felger J, Mister D, Liu T, Torres MA. A prospective study of quality of life in breast cancer patients undergoing radiation therapy. Adv Radiat Oncol. 2016;1:10-6.

24. Hofso K, Bjordal K, Diep LM, Rustoen T. The relationships between demographic and clinical characteristics and quality of life during and after radiotherapy: in women with breast cancer. Qual Life Res. 2014;23:2769-77.

25. Gartner R, Jensen MB, Nielsen J, Ewertz M, Kroman N, Kehlet H. Prevalence of and factors associated with persistent pain following breast cancer surgery. JAMA. 2009;302:1985-92.

26. Hopwood P, Haviland JS, Sumo G, Mills J, Bliss JM, Yarnold JR, et al. Comparison of patient-reported breast, arm, and shoulder symptoms and body image after radiotherapy for early breast cancer: 5-year follow-up in the randomised standardisation of breast radiotherapy (START) trials. Lancet Oncol. 2010;11:231-40.

27. Krishnan L, Stanton AL, Collins CA, Liston VE, Jewell WR. Form or function? Part 2. Objective cosmetic and functional correlates of quality of life in women treated with breast-conserving surgical procedures and radiotherapy. Cancer. 2001;91:2282-7.

28. Peintinger F, Reitsamer R, Stranzl H, Ralph G. Comparison of quality of life and arm complaints after axillary lymph node dissection vs sentinel lymph node biopsy in breast cancer patients. Br J Cancer. 2003;89:648-52.

29. Johnsson A, Fornander T, Rutqvist LE, Olsson M. Work status and life changes in the first year after breast cancer diagnosis. Work. 2011:38:337-46.

30. Casellas-Grau A, Ochoa C, Ruini C. Psychological and clinical correlates of posttraumatic growth in cancer: A systematic and critical review. PsychoOncology. 2017;26(12):2007-18.

\section{Submit your next manuscript to BioMed Central and we will help you at every step:}

- We accept pre-submission inquiries

- Our selector tool helps you to find the most relevant journal

- We provide round the clock customer support

- Convenient online submission

- Thorough peer review

- Inclusion in PubMed and all major indexing services

- Maximum visibility for your research

Submit your manuscript at www.biomedcentral.com/submit

) Biomed Central 